\title{
Visualization of bHLH transcription factor interactions in living mammalian cell nuclei and developing chicken neural tube by FRET
}

\author{
Chen Wang ${ }^{1}$, Wei Bian ${ }^{1}$, Caihong Xia ${ }^{1}$, Ting Zhang ${ }^{1}$, Francois Guillemot ${ }^{2}$, Naihe Jing ${ }^{1}$ \\ ${ }^{1}$ Key Laboratory of Stem Cell Biology, Institute of Biochemistry and Cell Biology, Shanghai Institutes for Biological Sciences, Chinese \\ Academy of Sciences; Graduate School of the Chinese Academy of Sciences, 320 Yue Yang Road, Shanghai 200031, China; ${ }^{2}$ Division \\ of Molecular Neurobiology, National Institute for Medical Research, The Ridgeway, Mill Hill, London NW7 1AA, UK
}

Members of the basic helix-loop-helix (bHLH) gene family play important roles in vertebrate neurogenesis. In this study, confocal microscopy-based fluorescence resonance energy transfer (FRET) is used to monitor bHLH protein-protein interactions under various physiological conditions. Tissue-specific bHLH activators, NeuroD1, Mash1, Neurogenin1 (Ngn1), Neurogenin2 (Ngn2), and ubiquitous expressed E47 protein are tagged with enhanced yellow fluorescence protein (EYFP) and enhanced cyan fluorescence protein (ECFP), respectively. The subcellular localization and mobility of bHLH fusion proteins are examined in HEK293 cells. By transient transfection and in ovo electroporation, four pairs of tissue-specific bHLH activators and E47 protein are over-expressed in HEK293 cells and developing chick embryo neural tube. With the acceptor photobleaching method, FRET could be detected between these bHLH protein pairs in the nuclei of transfected cells and developing neural tubes. Mash1/E47 and Ngn2/E47 FRET pairs show higher FRET efficiencies in the medial and the lateral half of chick embryo neural tube, respectively. It suggests that these bHLH protein pairs formed functional DNA-protein complexes with regulatory elements of their downstream target genes in the specific regions. This work will help one understand the behaviours of bHLH factors in vivo.

Cell Research (2006) 16:585-598. doi:10.1038/sj.cr.7310076; published online 15 June 2006

Keywords: bHLH, confocal microscopy, chick embryo neural tube, FRET, in ovo electroporation, photobleach

\section{Introduction}

Central nervous system (CNS) development, which consists of the production of a vast variety of neurons and glia, is one of the most hierarchical and intricate events of embryogenesis [1], A key issue in the neurogenesis of vertebrate embryos is understanding how multipotent progenitors integrate spatial and temporal signals to direct neural differentiation of diversified cell types. The basic helix-loop-helix (bHLH) transcriptional factors play a major part in this process [2,3], and they can be classified into three types according to their functions $[4,5]$. Class I, E

Correspondence: Naihe Jing

Tel: 86-21-54921381; Fax: 86-21-54921011;

E-mail: njing@sibs.ac.cn

Received 26 Sep 2005; revised 19 Dec 2005; accepted 21 Dec 2005; published online 15 Jun 2006 proteins, including two isoforms of $E 2 A$ gene product, E12 and $\mathrm{E} 47$, are ubiquitously expressed in all tissues and are capable of forming heterodimers with other bHLH proteins [6]; Class II, tissue-specific activators, are involved in cell fate determination, and bind DNA by forming heterodimers with E proteins [7, 8]; Class III, negative regulators such as the Id and Hes families, inhibits the Class II bHLH protein activity by interfering with their functional dimerization [9-11].

Class II tissue-specific bHLH activators demonstrate unique expression patterns during CNS development. Based on their temporal expression sequence, they can be further divided into neural determination factors such as the proneural genes, Mash1, Neurogenin1 (Ngn1) and Neurogenin2 (Ngn2), which are expressed in proliferating neural progenitors at the initiation of neuronal differentiation, and neural differentiation factors, such as NeuroD1 that is mainly expressed in young post-mitotic neurons 
undergoing neuronal differentiation $[4,5,12]$. Loss-offunction studies in mice have demonstrated the importance of these tissue-specific bHLH activators in the formation of specific populations of neurons [3]. Understanding how these regulatory proteins function will shed light on the mechanisms of nervous system development.

Class II tissue-specific bHLH activators function by forming heterodimers with $\mathrm{E}$ proteins, and bind to Eboxes with the consensus sequence of CANNTG in the promoter of target genes [13, 14]. The three-dimensional structure of the E47 protein bound to DNA showed a parallel, four-helix bundle with the basic region contacting the major groove of DNA $[15,16]$. However, there is still no detailed information on the interactions between different tissue-specific bHLH activators and E proteins in living mammalian cells and developing nervous system, and on the protein-DNA complex formations between bHLH factors and their cognate cis-elements in neural progenitors and post-mitotic young neurons.

Fluorescence resonance energy transfer (FRET) is a quantum mechanical process that involves energy transfer from a donor fluorophore to an appropriately positioned acceptor fluorophore. The efficiency of energy transfer varies with the inverse sixth power of the distance between donor and acceptor, thus limiting FRET to a short range of 1-10 nm [17]. Therefore, any significant FRET infers actual physical interactions between two proteins [18]. Combined with the green fluorescence protein (GFP)-based cell assay, FRET detected by the confocal microscopy provides a powerful tool for monitoring protein-protein interactions with high temporal/spatial resolution in living mammalian cells under various physiological conditions $[19,20]$.

In an attempt to establish an in vivo system capable of studying dynamic bHLH protein dimerization, we overexpressed bHLH factor-enhanced yellow fluorescence protein (EYFP)/enhanced cyan fluorescence protein (ECFP) fusion proteins in both human embryonic kidney (HEK) 293 cells and neural tubes of chick embryo, and observed FRET occurrence in living mammalian cells as well as in developing neural tissues.

\section{Materials and Methods}

\section{Construction of CFP and YFP fusion proteins}

ECFP and EYFP are the most widely used FRET pairs [21]. Because EYFP has a much stronger fluorescence intensity than ECFP, we made the larger E47 (654 amino acids) and EYFP fusion protein the acceptor fluorophore, and the smaller tissue-specific activators, NeuroD1 (357 amino acids), Mash1 (231 amino acids), Ngn1 (244 amino acids) and Ngn2 (263 amino acids), and ECFP fusion proteins the donor fluorophore to ensure comparative expression levels of donor and acceptor. ECFP-Nuc (Clontech), a specific nucleus-localized ECFP, was used as a negative control for FRET analysis in
HEK293T cells.

The EYFP-pcDNA3 was constructed by PCR amplification of EYFP coding region from the $\mathrm{pEYFP}$ expression vector (Clontech) with primers to generate $\mathrm{XhoI}$ and $\mathrm{XbaI}$ sites at the $5^{\prime}$ and $3^{\prime}$ ends, respectively. The PCR product was digested with the same enzymes and cloned into pcDNA3 (Invitrogen). The Myc tag fragment was digested from Myc-pcDNA3 [22] with BamHI and EcoRI, and inserted into corresponding sites of EYFP-pcDNA3 to produce the Myc-EYFP-pcDNA3 vector. The human E47 protein coding region was amplified by PCR with two EcoRI sites and inserted in-frame into Myc-EYFP-pcDNA3 to generate the Myc-tagged EYFP and E47 fusion protein expression construct, Myc-E47-EYFP.

The coding region of mouse NeuroD1 protein was amplified by PCR with two EcoRI sites and subcloned into the same sites of pECFP-N1 (Clontech) to construct the NeuroD1 and ECFP fusion protein expression vector, NeuroD1-ECFP. The HA-tagged mouse Ngn1 and Ngn2 protein coding regions in the HA-Ngn1-pcDNAI and HA-Ngn2-pcDNAI vectors were PCR-amplified with HindIII/EcoRI sites and inserted into the same sites of pECFP-N1 to produce the HA-tagged Ngn1, Ngn2 and ECFP fusion protein expression vectors, HA-Ngn1-ECFP and HA-Ngn2-ECFP. PCR was also used to amplify the mouse Mash1 coding region with $B g l \mathrm{II} / E c o R \mathrm{I}$ sites at both ends. The PCR product was then digested with $B g l \mathrm{II} / E c o R \mathrm{I}$ and inserted into BamHI/EcoRI sites of HA-Ngn1-pcDNAI to replace the Ngn1 coding region and construct HA-Mash1-pcDNAI. The HA-tagged Mash1 was cut with HindIII/EcoRI and ligated into the corresponding sites of pECFP-N1 to generate the HA-Mash1-ECFP fusion protein. The stop codons of bHLH proteins were mutated by primer design, and the sequence fidelity of all expression vectors were confirmed by DNA sequencing (BioAsia, China).

\section{Cell culture, transient transfection and protein analysis}

HEK293T cells were cultured in Dulbecco's modified Eagle's medium/F12 (DMEM/F12, Sigma) supplemented with 10\% fetal bovine serum (FBS, Hyclone). For plasmid transfection, $3 \mu \mathrm{g}$ DNA was used for a $60 \mathrm{~mm}$ cell culture dish. The DNA-calcium mixture was added drop-wise to cells and maintained in an incubator at $37{ }^{\circ} \mathrm{C}$ with $5 \% \mathrm{CO}_{2}$ for $8 \mathrm{~h}$. The medium was then replaced with fresh medium and cells were incubated for an additional 24-48 h before use [23].

Western blot analysis of ECFP and EYFP fusion proteins were performed as previously described [24]. The cell lysates were separated by SDS-PAGE, and transferred to nitrocellulose membrane (Amersham). The resulting blots were probed with mouse anti-HA (Santa Cruz) and anti-Myc (Santa Cruz) monoclonal antibodies, and rabbit anti-GFP (molecular probes) polyclonal antibodies, respectively.

Immunoprecipitations were performed as described previously [25]. Forty-eight hours after transfection, HEK293T cells were lysed with lysis buffer ( $120 \mathrm{mM} \mathrm{NaCl}, 0.5 \% \mathrm{NP}-40,100 \mathrm{mM} \mathrm{NaF}, 50 \mathrm{mM}$ Tris-Cl, $\mathrm{pH} 8.0$ ) and centrifuged at $10000 \times \mathrm{g}$ at $4{ }^{\circ} \mathrm{C}$ for $10 \mathrm{~min}$. To monitor the protein expression level, $10 \%$ of total cell lysates of each sample were used for Western blots.

\section{Subcellular localization of fusion proteins}

HEK293T cells grown on poly-L-lysine coated glass coverslips were transfected transiently with fusion protein expression vectors as described above. Forty-eight hours after transfection, the cells were fixed by $4 \%$ paraformaldehyde (PFA) in PBS at $4{ }^{\circ} \mathrm{C}$ for $30 \mathrm{~min}$ and stained with DAPI $(1 \mathrm{mg} / \mathrm{ml})$ for $3-5 \mathrm{~min}$ at room temperature. The 
cells were then washed twice with PBS and mounted onto slides with Mowoil (Calbiochem). All images were taken using an inverted confocal microscope (BioRad Radiance 2100 ) with a $60 \times$ oil objective lens (1.4 numeric aperture). Filter sets utilized were YFP [Excitation, $514 \mathrm{~nm}$ (Ar); Emission, 545/40 nm (PMT2)] and CFP [Excitation, $457 \mathrm{~nm}$ (Ar); Emission, 485/30 nm (PMT1)].

\section{Fluorescence recovery after photobleaching (FRAP) analysis of bHLH-EGFP fusions}

Cells were observed using BioRad Radiance 2100 confocal laser scanning microscope with a $60 \times$ oil objective lens. For bHLH-ECFP fusion proteins, cells were excited with $457 \mathrm{~nm}$ and emission was collected at 485/30 nm. For Myc-E47-EYFP, cells were excited at $514 \mathrm{~nm}$ and emission was collected at $545 / 40 \mathrm{~nm}$. Images were taken every second at a resolution of $512 \times 512$ pixels per inch. After the first four images, a selected rectangular region of fixed size in the nucleus was bleached with a set laser of maximal power for 50 iterations. Fluorescences in the bleached and unbleached regions were quantified at each time point with minimal laser power using lasersharp 2000 software. Data were plotted in a graph to show recovery of fluorescence in the bleached region, with pre-bleach intensity as 1.0 . At least 10 cells were measured and gave similar results $[26,27]$.

\section{FRET analysis of living cells}

FRET was quantified on the basis of the acceptor photobleaching method, developed for laser-scanning confocal microscopy [28-30]. HEK293T cells were co-transfected with different pairs of ECFP and EYFP fusion protein expression vectors. Conventional fluorescence microscopy was used to confirm fluorescence protein expression 24-48 h after transfection, and then cells were re-fed with serum-free DMEM/F12 medium before being imaged by confocal microscopy. For donor imaging, the CFP filter was set with excitation at $457 \mathrm{~nm}$ and emission at $485 / 30 \mathrm{~nm}$, while the YFP filter was set with excitation at $514 \mathrm{~nm}$ and emission at $545 / 40 \mathrm{~nm}$ for acceptor imaging. Images were created with a resolution of $512 \times$ 512 pixels per inch. Cells with low to moderate expression levels of both ECFP and EYFP fusion proteins were selected. To produce non-saturating fluorescence, the cells were first pre-scanned with a suitable laser intensity and voltage, and then images of the donor and acceptor were taken simultaneously. To detect FRET, cells with similar fluorescence intensity ratio of donor/acceptor were chosen and regions of interest (ROI1) within the fluorescence-expressing area of the nucleus were selected for photobleaching. In the same nuclei, a region with the similar fluorescence intensity as ROI1 was chosen as the unbleached control, ROI2. Seven pre-bleach images were taken first, then the ROI1 was bleached with the maximum 514 $\mathrm{nm}$ lasers for 6-10 iterations, and seven post-bleach images of the donor and acceptor were captured finally under the same conditions as those for the pre-bleach images [31]. Fluorescence intensity of the selected ROI was quantified at each time point by lasersharp 2000 software (BioRad) and was recorded in a spreadsheet to be imported in Excel.

FRET was also detected with the same method in fixed HEK293T cells. The only difference was that the cells were fixed by $4 \%$ PFA before analyzed.

The efficiency of FRET was assessed by measuring average donor fluorescence intensities before $\left(D_{\text {pre }}\right)$ and after $\left(D_{\text {post }}\right)$ photobleaching of the acceptor. The efficiency of FRET was calculated as $\mathrm{E}=\left(D_{\text {post }}{ }^{-}\right.$
$\left.D_{\text {pre }}\right) / D_{\text {post }}$ [28-31], where $D_{\text {pre }}$ is defined as the average fluorescence intensity of seven pre-images of the ROI, and $D_{\text {post }}$ is calculated as the average intensity of seven post-images. It is assumed that FRET did not occur where $D_{\text {post }}$ was less than $D_{\text {pre }}$. The result values are means \pm SEM of at least three independent experiments, each analyzing $2-3$ cells.

\section{In ovo chick embryo electroporation and FRET analysis}

Fertilized eggs were obtained from the Shanghai Academy of Agricultural Sciences (Shanghai, China). Experiments were carried out in accordance with the Guide for Care and Use of Laboratory Animals sponsored by the United States National Institute of Health. In ovo electroporation of chick embryo was performed as previously described [32]. Briefly, fertilized eggs were incubated at $38^{\circ} \mathrm{C}$, and the embryos were staged according to Hamburger and Hamilton [33] DNA solutions of expression vectors $(1.5 \mu \mathrm{g} / \mu \mathrm{l})$ with $0.05 \%$ fast green were injected into the lumen of the closed neural tube of chick embryo at stages 12,13 , and were electroporated into cells on one side of the neural tube by electrodes flanking the embryo. Squarewave current (six $30 \mathrm{~ms}$ pulses of $25 \mathrm{mV}$ ) was generated using BTX ECM830 Electro Square Porator ${ }^{\mathrm{TM}}$ (Genetronics Inc.) connected to $4 \mathrm{~mm}$ platinum electrodes. The embryos were then incubated at 38 ${ }^{\circ} \mathrm{C}$ for $24 \mathrm{~h}$, and collected at stages 17,18 . Surviving embryos were sacrificed and the expression of fusion proteins was examined by a fluorescence dissection microscope (Leica). Embryos with ECFP and EYFP expression in the neural tube were fixed in 4\% PFA in PBS for $1 \mathrm{~h}$ at $4{ }^{\circ} \mathrm{C}$, equilibrated in $20 \%$ sucrose in PBS overnight at 4 ${ }^{\circ} \mathrm{C}$, and embedded with Tissue-Tek OCT compound (Leica). These embedded tissues were sectioned at a thickness of $20 \mu \mathrm{m}$, and the tissue sections were examined under a conventional fluorescence microscope (Olympus). For each FRET pair, more than 100 fluorescence-expressing cells from different embryos were counted and the percentage of cells located within the medial or lateral half of the neural tube was calculated. FRET analysis of neural tube sections was performed as described above. Statistical analyses were carried out with the student's $t$-test. *: $P<0.05, * *: P<0.01$.

\section{Results}

\section{Characterization of CFP and YFP fusion protein expres- sion}

To detect bHLH protein interactions via FRET, tissuespecific activators, NeuroD1, Mash1, Ngn1 and Ngn2, were fused with the donor fluorophore, ECFP, and the E47 protein was fused with the acceptor fluorophore, EYFP. Both ECFP and EYFP were fused at the C-terminus of these bHLH factors to avoid perturbations of the function of DNA-binding domain (Figure 1A).

Western blots were used to determine fusion protein expression levels in mammalian cells. In HEK293T cells transfected with NeuroD1-ECFP expression vector, the fusion protein could be detected by anti-GFP antibody, which could recognize EGFP variants, ECFP and EYFP. The other fusion proteins, HA-Mash1-ECFP, HA-Ngn1ECFP, HA-Ngn2-ECFP and Myc-E47-EYFP were detected by the anti-HA and anti-Myc antibodies, as well as the 
A

HAMash1ECFP

HANgn1ECFP

HANgn2ECFP
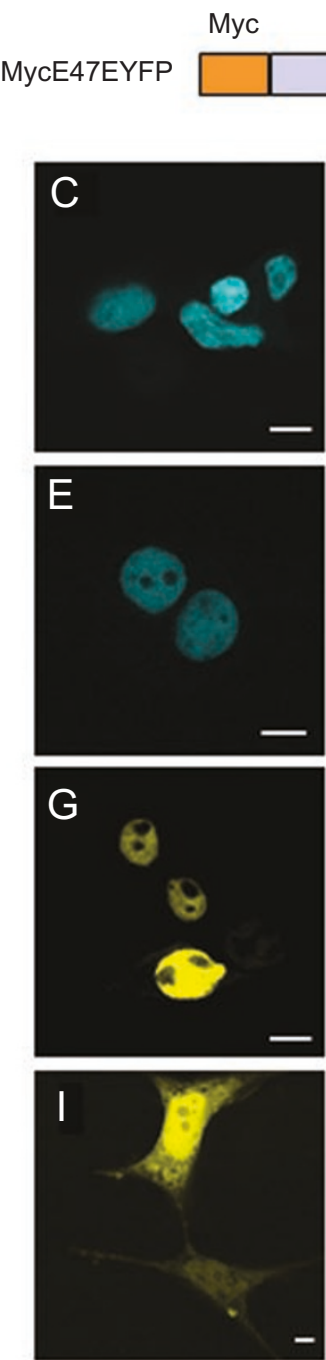

B

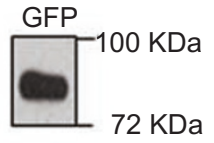

C
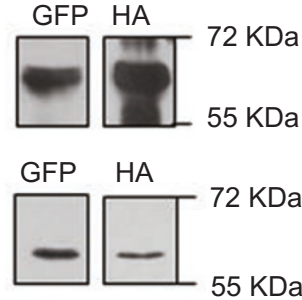

GFP HA
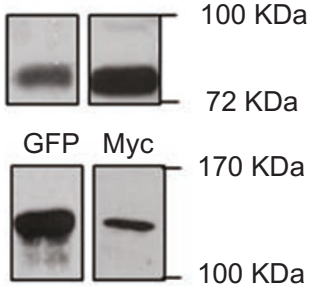

EYFP
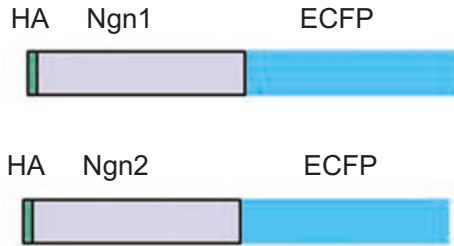

E47
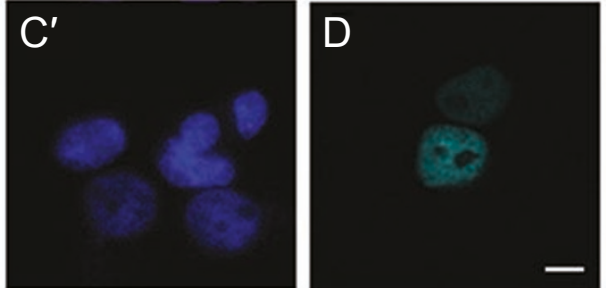

\section{$D^{\prime}$}
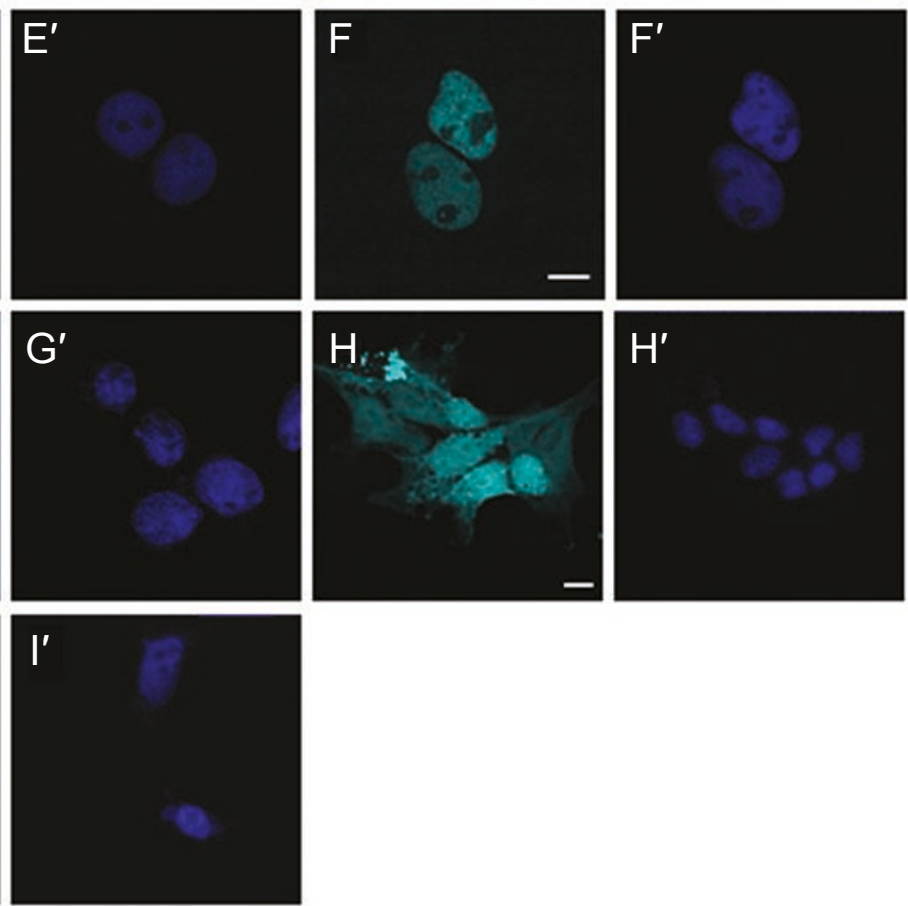

Figure 1 Characterization of bHLH fusion proteins. (A) Schematics of expression vectors for NeuroD1-ECFP, HA-Mash1-ECFP, HA-Ngn1-ECFP, HA-Ngn2-ECFP and Myc-E47-EYFP fusion proteins. (B) Western blots analysis of bHLH-GFP fusion proteins. Antibodies used are shown at the tops of the bands. Subcellular localization of NeuroD1-ECFP (C) HA-Mash1-ECFP (D) HA-Ngn1ECFP (E) HA-Ngn2-ECFP (F) Myc-E47-EYFP (G) fusion proteins and control plasmids, pECFP-N1 (H) EYFP-pcDNA3 (I) in HEK293T cells. The corresponding DAPI stainings are shown in $\mathbf{C}^{\prime}-\mathbf{I}^{\prime}$. Scale bar: $10 \mu \mathrm{m}$. 
A

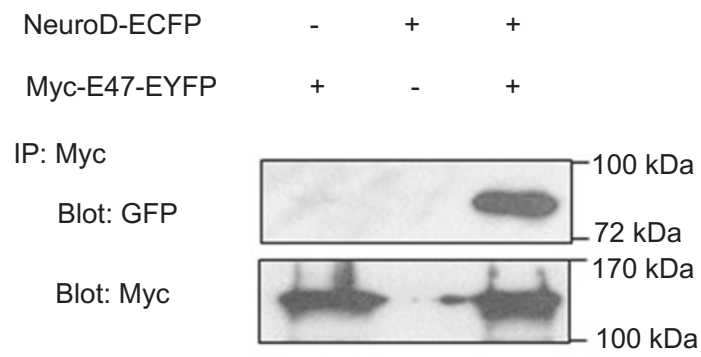

TCL:

Blot: Myc

Blot: GFP

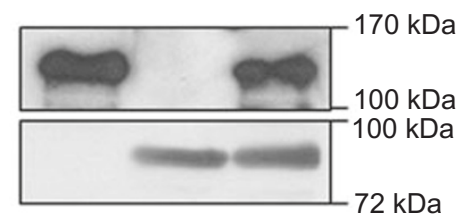

B

HA-Mash1-ECFP HA-Ngn1-ECFP HA-Ngn2-ECFP

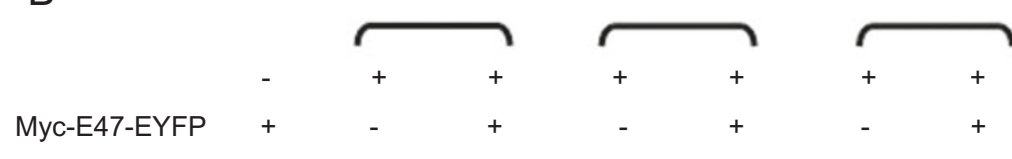

IP: HA

Blot: Myc
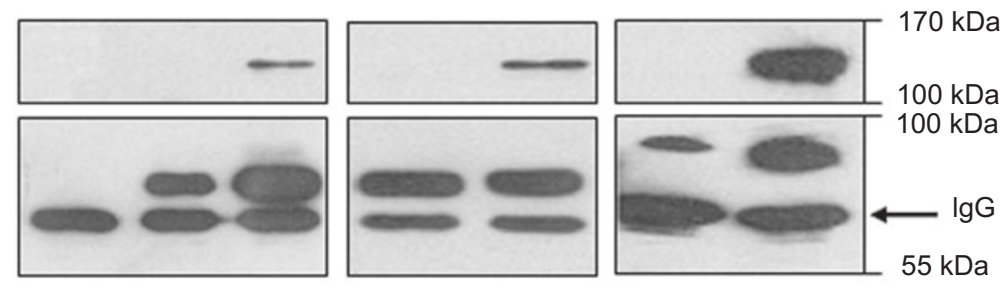

Blot: HA
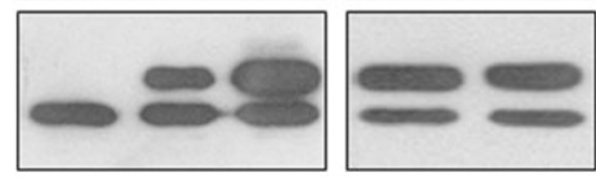

TCL:

Blot: Myc
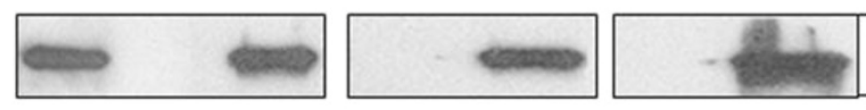

$170 \mathrm{kDa}$

Blot: $\mathrm{gyc}$
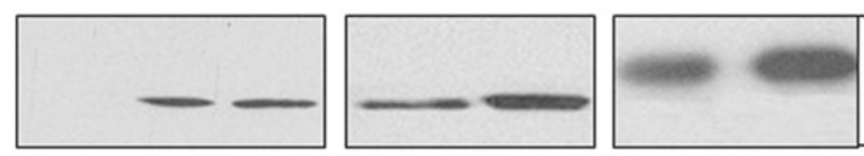

$100 \mathrm{kDa}$

$100 \mathrm{kDa}$

Blot: HA

Figure 2 Co-immunoprecipitation of Myc-E47-EYFP and neural bHLH-ECFP fusion proteins. (A) HEK293T cells were transfected with expression vectors of both Myc-E47-EYFP and NeuroD1-ECFP fusion proteins, or with either vector alone. The cell lysates were immunoprecipitated with anti-Myc antibody and immunoblotted with anti-GFP and anti-Myc antibodies. Total cell lysates (TCL) were immunoblotted with the same antibodies as loading controls. (B) HEK293T cells were co-transfected with fusion protein expression vectors of Myc-E47-EYFP and HA-Mash1-ECFP (left panel), Myc-E47-EYFP and HA-Ngn1-ECFP (middle panel) and Myc-E47-EYFP and HA-Ngn2-ECFP (right panel), or with either vector alone. The cell lysates were immunoprecipitated with anti-HA antibody, and immunoblotted with anti-Myc and anti-HA antibodies. TCL were immunoblotted with the same antibodies as loading controls.

anti-GFP antibody. Molecular weights of the fusion proteins recognized by anti-HA or anti-Myc antibodies were identical to those of fusion proteins recognized by anti-GFP antibody (Figure 1B). No protein band was detected in the non-transfected control cells (data not shown).

Confocal microscopy was used to examine the subcellular localization of fusion proteins. As shown in Figure
$1 \mathrm{C}-\mathrm{G}$, all these fusion proteins were localized in the nuclei of the transfected cells and displayed a typical speckled pattern as observed previously for many transcriptional factors [34]. In contrast, the fluorescence proteins encoded by the control expression vectors, pECFP-N1 and EYFPpcDNA3, were observed in both cytoplasm and nucleus (Figure 1H-I). No fluorescence was detected in non-trans- 
A
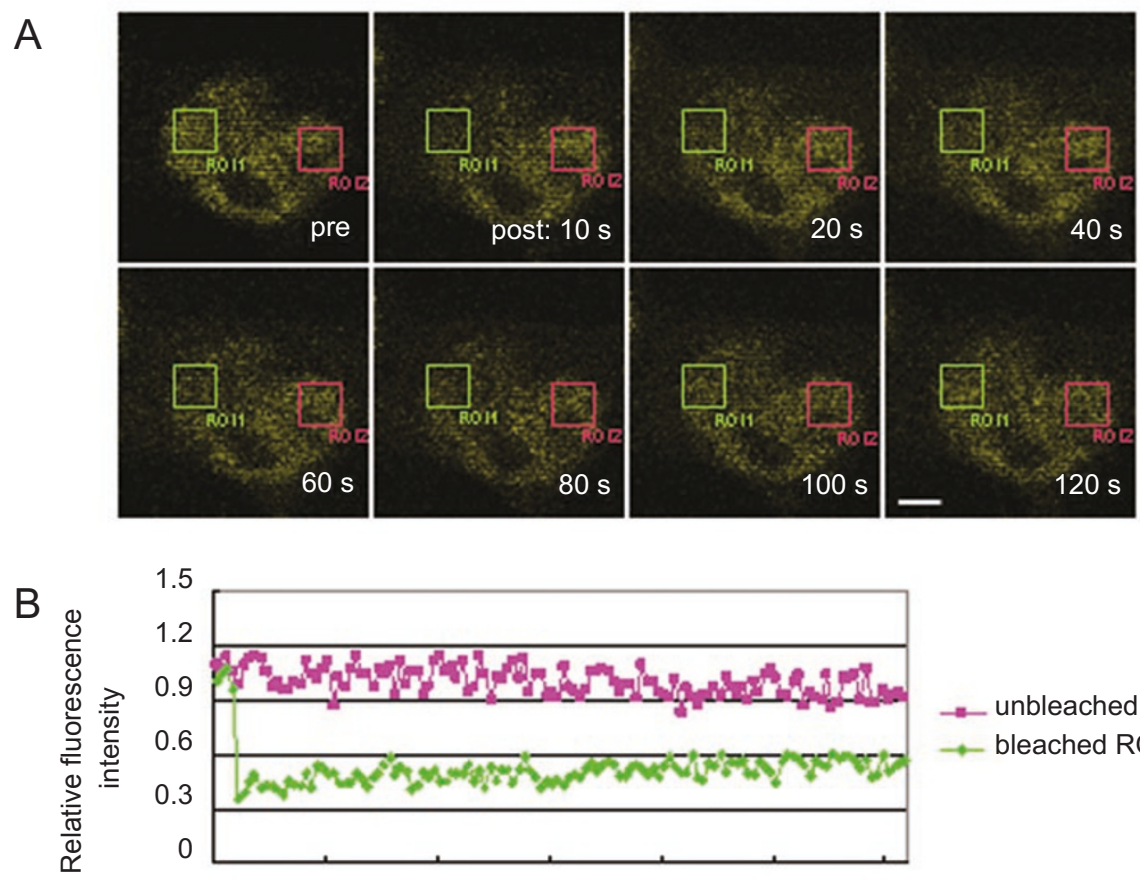

1.5
1.2
0.9
0.6
0.3

1.5
1.2
0.9
0.6
0.3
0
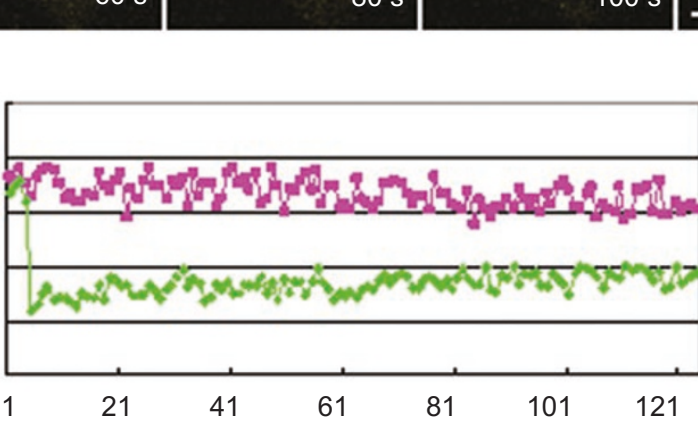

Figure 3 FRAP analysis of Myc-E47-EYFP fusion protein in the nuclei of living HEK293T cells. HEK293T cells were transiently transfected with expression plasmid encoding Myc-E47-EYFP and subjected to quantitative FRAP analysis. (A) Photobleaching was done in ROI1 and images were taken in the indicated time. (B) Fluorescence intensities for the bleached (green line) and unbleached regions (red line) were measured and plotted over time. Scale bar: $2 \mu \mathrm{m}$.

fected cells (data not shown). These results suggest that the N-terminal HA- or Myc-tagged and C-terminus CFP or YFP-fused bHLH fusion proteins were expressed in mammalian cells and localized in the nucleus, as expected from their activities as transcriptional factors.

Tissue-specific bHLH activators could be co-immunoprecipitated with $E 47$ protein

To confirm protein-protein interaction between fusion proteins of the tissue-specific bHLH activators and E47 protein, four different pairs of fusion protein expression vectors were co-transfected into HEK293T cells, and immunoprecipitation (IP) and Western blot (Blot) assays were performed. The results indicated that co-immunoprecipitation could be detected in the cells transfected with both NeuroD1-ECFP and Myc-E47-EYFP plasmids, but not in the cells transfected with either vector alone (Figure 2A). Similarly, the co-immunoprecipitation occurred between HA-Mash1-ECFP and Myc-E47-EYFP, HA-Ngn1-ECFP and Myc-E47-EYFP, and HA-Ngn2-ECFP and Myc-E47EYFP fusion protein pairs in the cells co-transfected with both plasmids, but not in the cells transfected with either vector alone (Figure 2B). These results suggest that the tis- sue-specific bHLH activators, NeuroD1, Mash1, Ngn1 and Ngn2, did form protein complexes with the ubiquitously expressed partner, E47 protein, in mammalian cells.

\section{The low mobility of Myc-E47-EYFP fusion protein in HEK293T cells}

FRAP was used to determine the dynamic property of Myc-E47-EYFP fusion protein in living HEK293T cells (Figure 3). HEK293T cells expressing yellow fluorescence were irreversibly photobleached by the high-powered 514 $\mathrm{nm}$ laser in selected area of the nucleus with confocal microscopy (Figure 3A, ROI1, green boxes). After photobleaching, the fluorescence intensities in the bleached (ROI1) and unbleached areas (ROI2, red boxes) were recorded by sequential imaging scans at different time points. The fluorescence intensity in ROI1 was reduced significantly and recovered very slowly up to $120 \mathrm{~s}$, while the fluorescence in ROI2 did not change much during the same period (Figure 3A). The intensities in ROI1 and ROI2 were also measured at each time points, plotted and shown as the green and red lines, respectively (Figure 3B). The fluorescence decreased to $30 \%$ of the pre-bleached intensity in ROI1 immediately after photobleaching, and recovered 
Table 1 Fluorescence intensity ratio for four FRET pairs

\begin{tabular}{|c|c|c|c|c|}
\hline & Pre-bleach intensity & HEK293 & Medial half & Lateral half \\
\hline \multirow[t]{3}{*}{ Mash1-E47 } & Don ROI1/ROI2 & $1.12 \pm 0.03$ & $1.10 \pm 0.17$ & $1.00 \pm 0.13$ \\
\hline & Acc ROI1/ROI2 & $1.10 \pm 0.11$ & $1.12 \pm 0.25$ & $0.98 \pm 0.17$ \\
\hline & Don/Acc ROI1 & $0.62 \pm 0.09$ & $0.66 \pm 0.23$ & $0.60 \pm 0.18$ \\
\hline \multirow[t]{3}{*}{ NeuroD-E47 } & Don ROII/ROI2 & $0.98 \pm 0.11$ & $0.95 \pm 0.10$ & $1.02 \pm 0.13$ \\
\hline & Acc ROI1/ROI2 & $0.86 \pm 0.17$ & $0.99 \pm 0.23$ & $1.02 \pm 0.13$ \\
\hline & Don/Acc ROII & $0.56 \pm 0.01$ & $0.67 \pm 0.21$ & $0.65 \pm 0.05$ \\
\hline \multirow[t]{3}{*}{ Ngn1-E47 } & Don ROI1/ROI2 & $1.00 \pm 0.14$ & $0.98 \pm 0.12$ & $0.95 \pm 0.10$ \\
\hline & Acc ROI1/ROI2 & $0.99 \pm 0.15$ & $0.99 \pm 0.15$ & $0.99 \pm 0.23$ \\
\hline & Don/Acc ROII & $0.55 \pm 0.12$ & $0.67 \pm 0.14$ & $0.66 \pm 0.15$ \\
\hline \multirow[t]{3}{*}{ Ngn2-E47 } & Don ROI1/ROI2 & $0.96 \pm 0.17$ & $1.03 \pm 0.10$ & $1.00 \pm 0.12$ \\
\hline & Acc ROII/ROI2 & $1.10 \pm 0.17$ & $0.92 \pm 0.24$ & $1.17 \pm 0.24$ \\
\hline & Don/Acc ROII & $0.58 \pm 0.17$ & $0.67 \pm 0.16$ & $0.65 \pm 0.24$ \\
\hline
\end{tabular}

Notes: Don ROI1/ROI2: ratio of pre-bleach donor fluorescence intensity within ROI1 and ROI2. Acc ROI1/ROI2: ratio of pre-bleach acceptor fluorescence intensity within ROI1 and ROI2. Don/Acc ROI1: ratio of pre-bleach donor and acceptor fluorescence intensity within ROI1. Relative fluorescence intensity for each FRET pair were given by BioRad Lasersharp 2000 software and recorded in Excel. The data shown are means \pm SEM.

to $50 \%$ of its pre-bleached intensity after $30 \mathrm{~s}$. In ROI 2 regions, however, the fluorescence decreased slightly to $90 \%$ of the pre-bleached intensity after $120 \mathrm{~s}$ of repeated scanning (Figure 3B).

As ECFP is not sensitive to photobleaching [35, 36], no obvious fluorescence loss was observed for all four ECFP fusion proteins even after 100 iterations of photobleaching with the maximum laser power (data not shown). However, the problem considered most in FRET analysis of living cell is the acceptor mobility, as photobleaching of acceptor fluorophore will cause inhomogeneity in the cellular fluorescent population [37]. Our results showed that the low mobility of acceptor, Myc-E47-EYFP fusion protein, will not interfere with FRET detection in living mammalian cells by the acceptor photobleaching method.

FRET occurs between fusion proteins of tissue-specific bHLH activators and E47 protein in the nuclei of living mammalian cells

To visualize direct protein-protein interactions between the tissue-specific bHLH activators and E47 protein, four pairs of fusion protein expression vectors were co-transfected into HEK293T cells, and fluorescence intensities in the nuclei of living cells were measured with confocal microscopy (Figure 4). As the quantitative measurement of FRET efficiency depends on the consistent expression level of donor and acceptor proteins, cells with similar cyan/yellow fluorescence intensity were selected, and the ratios of pre-bleach donor and acceptor fluorescence intensity were within the range of $0.55-0.67$ (Table 1).
Taking the Mash1/E47 fusion protein pair as an example, an acceptor photobleaching region (ROI1, green boxes) and an unbleached control region with similar fluorescence density (ROI2, red boxes) were selected (Figure 4A, Table 1). The intensity of yellow fluorescence within ROI1 was reduced in the acceptor post-bleaching image, demonstrating the bleach efficiency. The yellow fluorescence in ROI1 showed little recovery after the photobleaching, probably due to the low mobility of E47 fusion protein. (Figure 4A, lower panel). The blue fluorescence within the same ROI1 increased in the donor post-bleaching image, revealing donor dequenching and the occurrence of FRET between acceptor and donor (Figure 4A, upper panel). During the process of FRET analyzing, the fluorescence intensities of acceptor and donor within ROI1 (green lines in Figure 4 A') and ROI2 (red lines in Figure 4 A') were captured at each time point before and after $514 \mathrm{~nm}$ laser photobleaching. Consistently, decreased acceptor intensities (green lines in the lower panel) and increased donor intensities (green lines in the upper panel) could be observed. As a control, fluorescence intensities of acceptor and donor within ROI2 (red lines in Figure 4A') were only slightly changed. Similarly, increased donor fluorescence intensities were also detected after photobleaching in NeuroD1/E47, Ngn1/E47 and Ngn2/E47 fusion protein pairs, indicating that the FRET occurred between these fusion proteins (Figure 4BD). FRET efficiencies of each fusion protein pair from 8 to 12 cells in three independent experiments are $20-30 \%$ (Figure 5F). A nucleus localized ECFP, ECFP-Nuc, was co-transfected with Myc-E47-EYFP into HEK293T cells as 
A

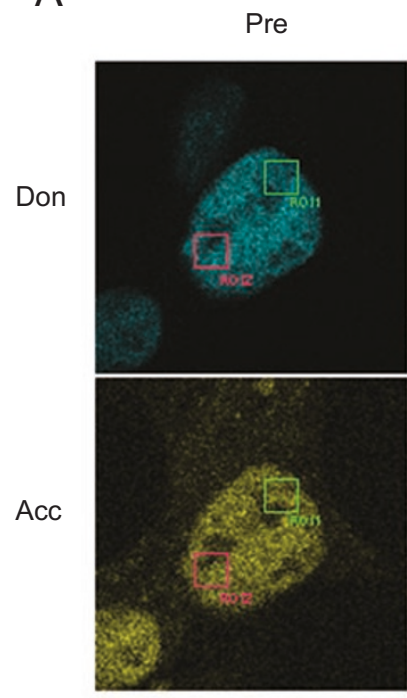

B
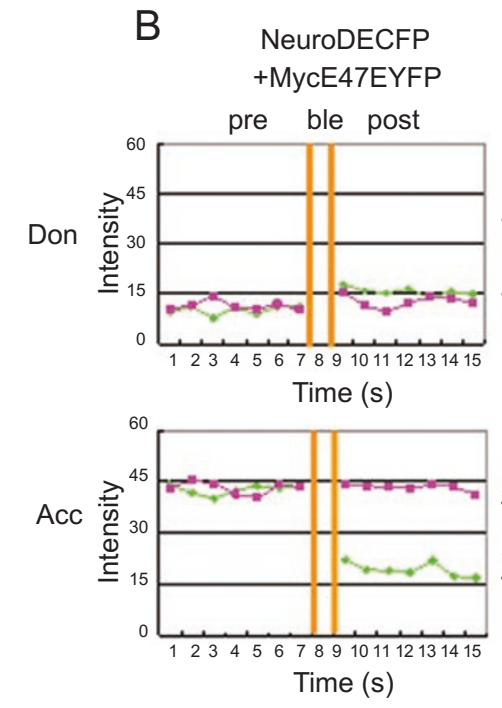

+MycE47EYFP

Post

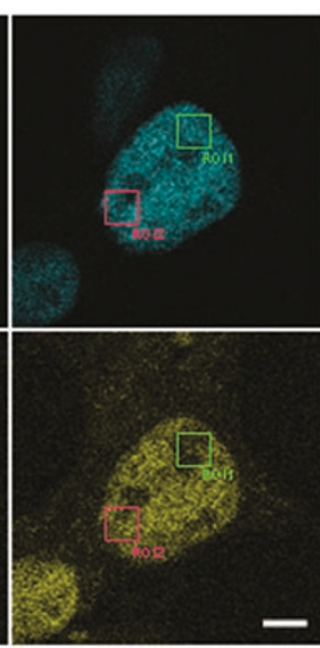

C HANgn1ECFP +MycE47EYFP
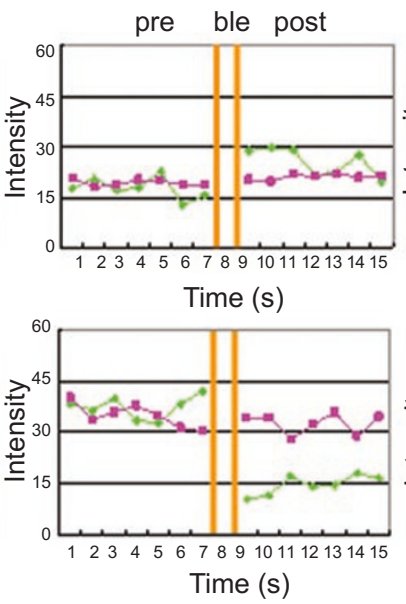

$A^{\prime}$
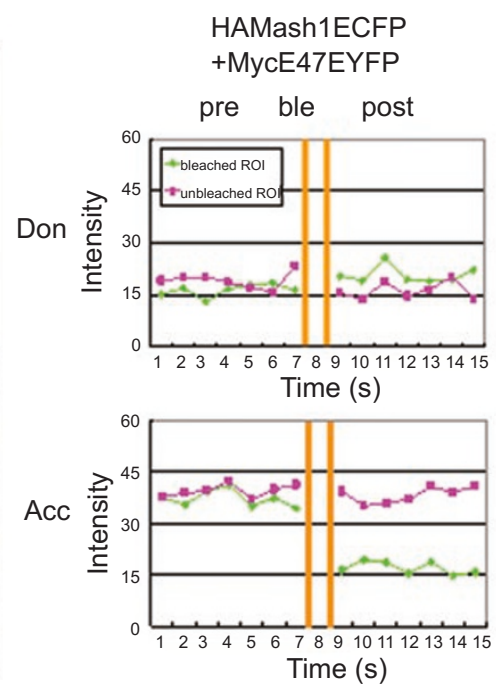

D HANgn2ECFP +MycE47EYFP

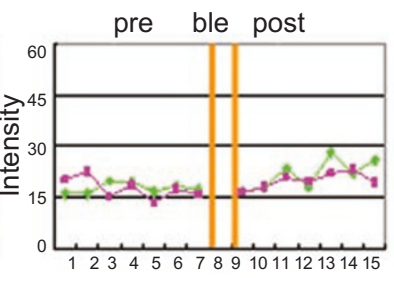

Time (s)

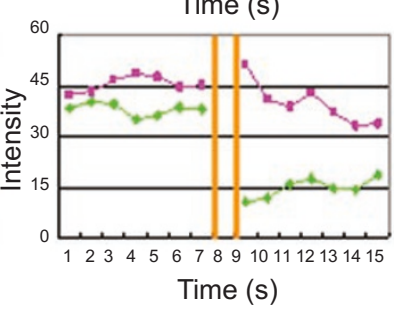

E

ECFP-Nuc+MycE47EYFP

pre

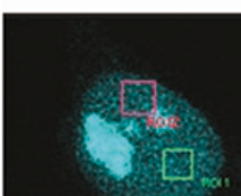

Acc

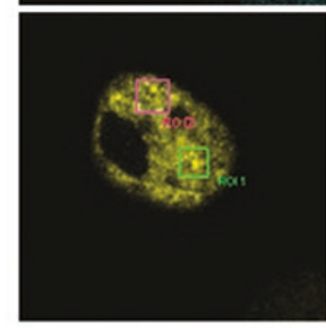

post
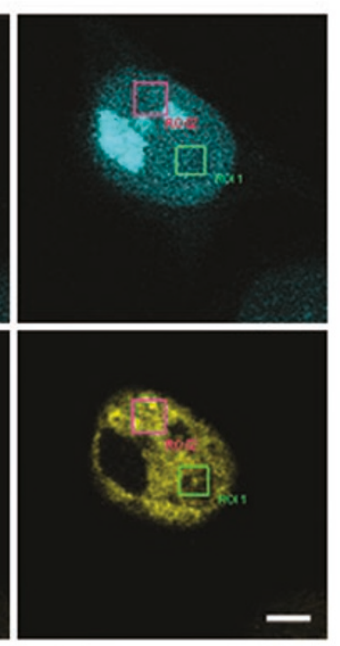

E'

ECFP-NuC + MycE47EYFP
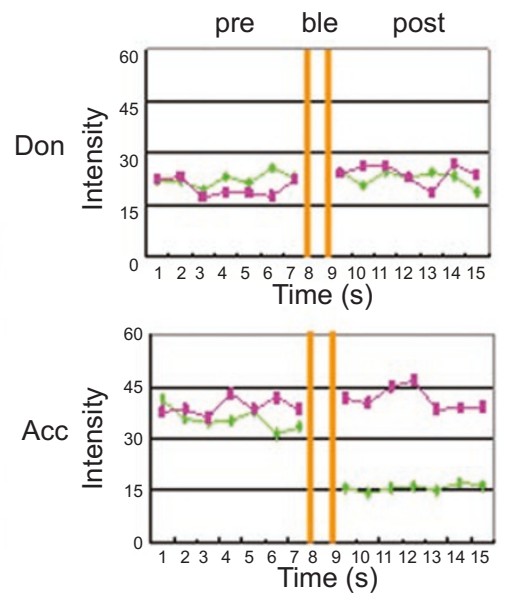
the negative control. No increased donor intensities could be detected within ROI1 after photobleaching (Figure 4E and E'). Thirteen out of sixteen cells showed lower average $D_{\text {post }}$ compared with average $D_{\text {pre }}$, suggesting that no FRET occurred between these fusion proteins. The FRET efficiency of other three cells was $3.755 \pm 2.198 \%$, significantly lower than that of bHLH fusion protein pairs.

To further validate the FRET data in living cells, we did the same FRET analysis in fixed HEK293T cells for all four pairs of fusion proteins, and found that FRET did occur in these cells, and there was no statistical difference in FRET efficiencies between living and fixed cells (Figure 5F). Altogether, these results suggest that interactions between fusion proteins of tissue-specific bHLH activators and E47 protein occurred in the nuclei of living mammalian cells.

FRET occurs between fusion proteins of tissue-specific bHLH activators and E47 protein in chick embryo neural tube

The tissue-specific bHLH activators, Mash1, Ngn1, Ngn2 and NeuroD1 play significant roles during vertebrate neurogenesis $[3,38]$. Studying protein-protein interactions of these factors in developing CNS could provide insights into the mechanism of their functions. These four fusion protein pairs were in ovo electroporated into chick embryos at stages 11,12 , and embryos were collected at stages 17 , 18. For each pair, 5-9 embryos expressing fluorescence were obtained (Figure 5A). Analysis of sections of electroporated embryos showed that expression of fluorescent fusion proteins was restricted to neural tubes (Figure 5B). For these four pairs, most of the fluorescence-positive cells localized in the lateral half of neural tube, and less than $20 \%$ of them existed in the medial half (Figure $5 \mathrm{E}$ ). The fluorescence expression levels of the cells localised in the lateral and medial were similar (arrow in Figure 5C-D and data not show).

Confocal microscopy was used to analyze FRET oc-

Figure 4 Detection of FRET between bHLH fusion protein pairs in the nuclei of living HEK293T cells. HEK293T cells were co-transfected with expression vectors of Mash1/E47 (A, $\left.\mathbf{A}^{\prime}\right)$, NeuroD1/E47 (B), Ngn1/E47 (C), Ngn2/E47 (D) and ECFP-Nuc/E47 (E) fusion protein pairs. ROI1 (green boxes) was selected as a photobleaching region, and ROI2 (red boxes) served as an unbleached control. The donor and corresponding acceptor images of Mash1/E47 pair (A) and ECFP-Nuc/E47 pair (E) were taken before and after photobleaching as the pre- (left panel) and post-bleaching (right panel) images. $\left(\mathbf{A}^{\prime}\right)$, (B-D) and (E') illustrate fluorescence intensities of ROI1 (green lines) and ROI2 (red lines) at each time point during the process of FRET analysis for Mash1/E47 (A'), NeuroD1/E47 (B), Ngn1/E47 (C), Ngn2/E47 (D) and ECFP-Nuc/E47 (E'). Abbreviations: Don: donor; Acc: acceptor; ble: photobleaching. Scale bar: $2 \mu \mathrm{m}$. currence in the electroporated neural tubes. The yellow fluorescence of Myc-E47-EYFP fusion protein co-localized with the cyan fluorescence of HA-Ngn1-ECFP fusion protein in the nuclei of neural progenitors and post-mitotic young neurons (Figure 5C-D). Taking the Ngn2/E47 fusion protein pair in the cells in the medial half as an example, the donor fluorescence intensities increased after photobleaching in ROI1 (green boxes in Figure 5G and green lines in Figure 5G', upper panel), indicating the occurrence of FRET between this pair of fusion proteins. The other fusion protein pairs showed similar results in the medial half cells (Figure 5H-J). To distinguish regional difference of fusion protein interactions in chick neural tubes, the FRET efficiencies of medial and lateral half localized cells were analyzed separately. The calculated FRET efficiencies of four FRET pairs, each from an average of 8-14 cells from different embryos, revealed that Mash1/E47 pair in the medial half cells produced much higher FRET efficiency than that in the lateral half cells and HEK293T cells. On the contrary, the FRET efficiency of Ngn2/E47 pair in the lateral half cells was significantly higher than that in the medial half cells and HEK293T cells. The NeuroD1/E47 and Ngn1/E47 pairs did not show difference among these four conditions (Figure 5F).

Taken together, these results suggest that protein-protein interactions occurred between fusion proteins of tissuespecific bHLH activators and E47 protein in the developing neural tubes of chick embryo, and Mash1/E47 and Ngn2/E47 fusion protein pairs apparently formed more compact complexes in specific regions of neural tubes than in HEK293T cells.

\section{Discussion}

Neural-specific bHLH activators function as master regulators in vertebrate neurogenesis. They are sufficient to initiate neuronal differentiation programs in non-neural cells [39-41]. Genetic studies revealed that these proteins are functionally divergent during nervous system development. Targeted disruption of Mash1 in mice resulted in neurogenesis defects in multiple regions of the nervous system, including the ventral telencephalon and olfactory sensory epithelium [42-44]. Ngn1 or Ngn2 single knockout mice showed complementary loss of cranial sensory ganglia, whereas the Ngn1/2 double knockout mice lacked the spinal sensory ganglia as well as a majority of ventral spinal cord neurons, due to, as for Mash1, an early defect in neurogenesis $[40,45,46]$. NeuroD1 null mice have defects in the granule layers of the cerebellum and hippocampus, and in the inner ear sensory neurons because of a later function of NeuroD1 in neuronal differentiation $[47,48]$. Understanding the mechanism of how different 

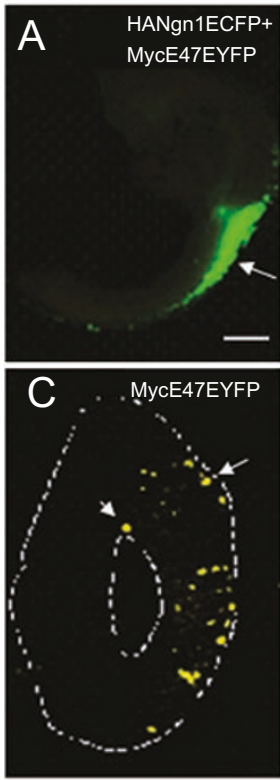

G

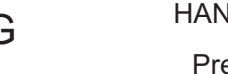

Pre

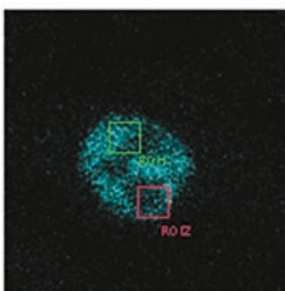

CC

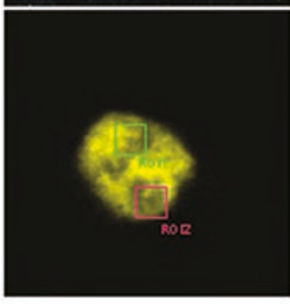

$\mathrm{H}$

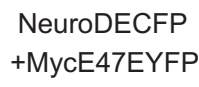

pre ble post

Don

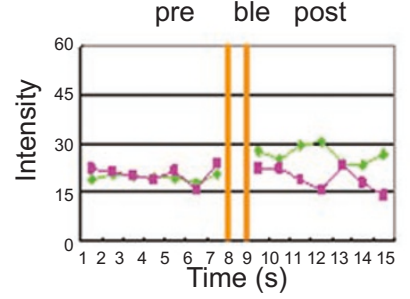

Acc

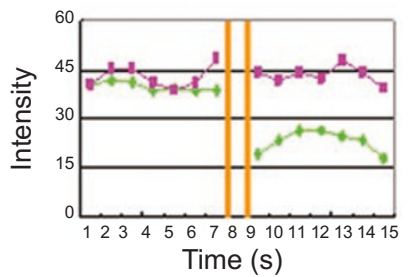

HANgn1ECFP+

MycE47EYFP

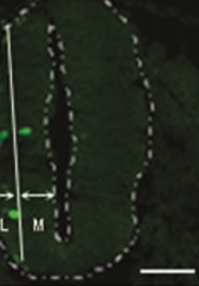

D ... HANgn1ECFP

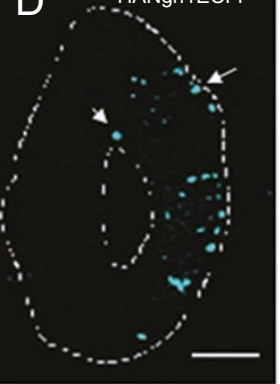

E

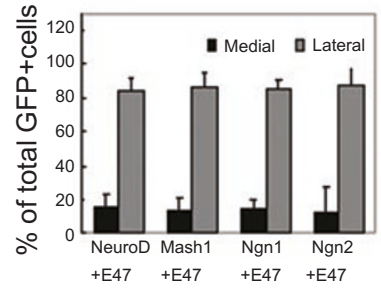

F

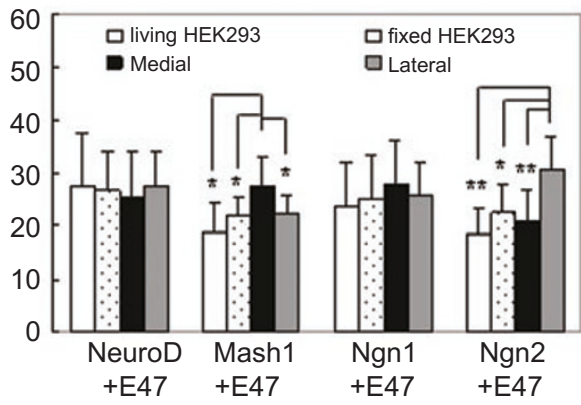

HANgn2ECFP
G' $\quad+$ MycE47EYFP

pre ble post

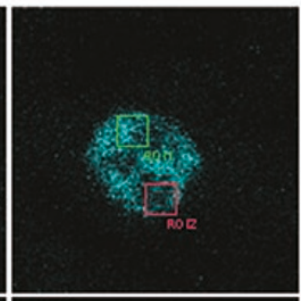

Don

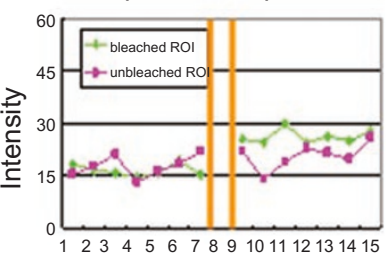

Time (s)

Acc

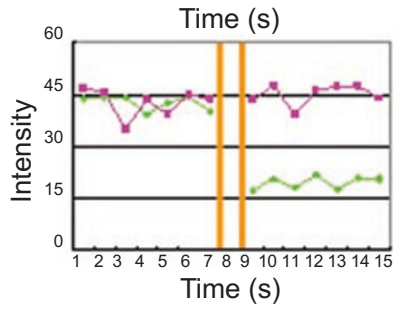

J HANgn1ECFP

+ MycE47EYFP

+MycE47EYFP
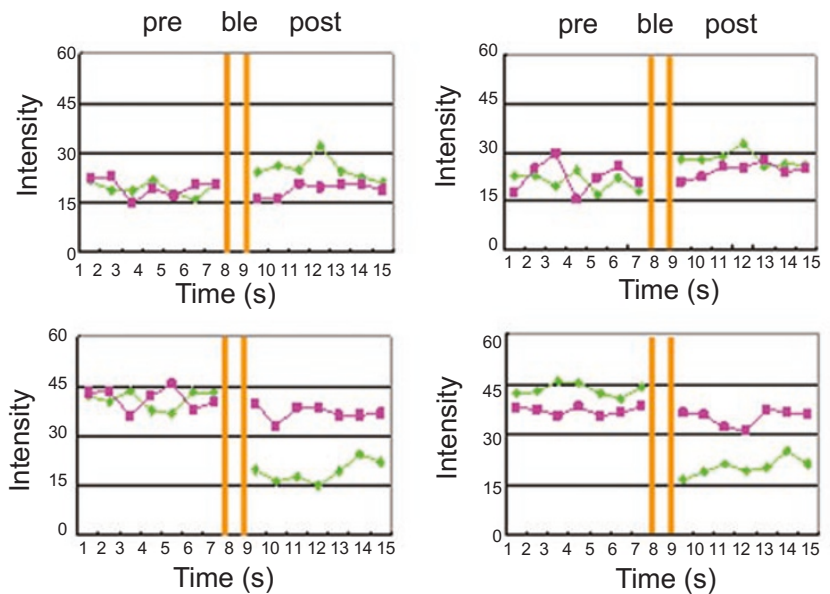
neural bHLH factors integrate positional information into the process of neurogenesis will facilitate the generation of multiple types of neural cells from pluripotent stem cells in vitro.

The recently developed GFP-based FRET technique provides a unique means of detecting protein-protein interactions in living cells. FRET efficiency is a direct reflection of the distance between donor and acceptor proteins, and can be used to measure the strength of interaction of two proteins under various physiological conditions. In this study, the FRET analysis of protein-protein interactions between different neural bHLH factors and E47 protein in HEK293 cells showed that Class II tissuespecific bHLH activators were able to form dimers with E47 protein effectively in the nuclei of living mammalian cells (Figure 4).

The GFP-based FRET technique has been limited

Figure 5 Detection of FRET between bHLH fusion proteins in the neural tube of chick embryos. (A) Expression vectors of HA-Ngn1ECFP and Myc-E47-EYFP fusion proteins were in ovo electroporated into chick embryos at stages 11-12, and embryos collected at stages 17-18. Fluorescence could be detected in the neural tube of electroporated embryos (arrow). Embryos with ECFP and EYFP expression in the neural tube were sectioned and examined by fluorescence microscopy. The neural tube was outlined with white dashed lines and the dorsal is to the top. The solid white line showed the border of the medial (M) and lateral (L) half (B). The percentage of cells located within medial or lateral half was determined (E). Confocal microscopy showed the co-localization of Myc-E47-EYFP (C) and HA-Ngn1-ECFP (D) fusion proteins in the nuclei of neural progenitors and post-mitotic young neurons in chick neural tubes. Note that protein expression levels of medial and lateral half cells were similar (arrow). For FRET analysis, the neural tubes of chick embryo were in ovo electroporated with expression vectors of $\mathrm{Ngn} 2 / \mathrm{E} 47\left(\mathbf{G}, \mathbf{G}^{\prime}\right)$, NeuroD1/E47 (H), Mash1/E47 (I) and Ngn1/E47 (J) fusion protein pairs. (G) ROI1 (green boxes) in the nucleus of fluorescence expressing cells in the neural tube was selected as a photobleaching region, and ROI2 (red boxes) served as an unbleached control. The donor and corresponding acceptor images of Ngn2/E47 pair were taken before and after photobleaching as the pre- (left panel) and post-bleaching (right panel) images. (G') and (H-J) illustrate fluorescence intensities of ROI1 (green lines) and ROI2 (red lines) at each time point during the process of FRET analysis for Ngn2/E47 (G'), NeuroD1/ E47 (H), Mash1/E47 (I) and Ngn1/E47 (J). The calculated FRET efficiencies for different fusion protein pairs in living HEK293T cells [NeuroD1/E47 ( $n=8)$, Mash1/E47 $(n=12), \operatorname{Ngn1/E47~}(n=9)$ and Ngn2/E47 $(n=10)]$, in fixed HEK293T cells [NeuroD1/E47 $(n=7)$, Mash1/E47 $(n=10), \operatorname{Ngn1/E47~}(n=10)$ and Ngn2/E47 $(n=8)]$, in the medial half of chick neural tube [NeuroD1/E47 $(n=12)$, Mash1/E47 $(n=12), \operatorname{Ngn} 1 / \mathrm{E} 47(n=10)$ and $\operatorname{Ngn} 2 / \mathrm{E} 47(n=8)]$, and in the lateral half of chick neural tube [NeuroD1/E47 $(n=14)$, Mash1/E47 $(n=8)$, Ngn1/E47 ( $n=8)$ and Ngn2/E47 ( $n=9)$ ] were shown in (F). Scale Bar for (A) is $1 \mathrm{~mm}$, for (B), (C) or (D) is $50 \mu \mathrm{m}$, for (G) is $2 \mu \mathrm{m}$. previously to analysis in cultured cells probably owing to the low transfection efficiency of tissues and organs. Meantime, it is important to establish a genuine in vivo system to study bHLH protein interactions in the developing embryo. After electroporated in ovo into the neural tubes of chick embryos, effective expression of fluorescent proteins were detected (Figure 5A). ECFP and EYFP fusion proteins co-localized in the nuclei of neural progenitors and post-mitotic neurons in electroporated neural tubes (Figure 5B-D), and FRET occurrence could be measured readily in these cells (Figure 5G-J). This is the first detection and demonstration of protein-protein interactions by GFP-based FRET technology in developing neural tissues.

For the four FRET pairs, most of the fluorescence expressing cells localized in the lateral half of the neural tube (Figure 5B and E), which consists mainly of post-mitotic, differentiating young neurons [49]. The most likely explanation of this interesting pattern is that overexpression of proneural genes may induce neural progenitor differentiation and promote their migration from the medial to the lateral half [50]. However, $20 \%$ of cells with similar amounts of bHLH protein expression did stay in the medial half (arrow in Figure 5C-D and data not shown); this was probably owing to the different intracellular competence between these cells and the migrating cells. Studies of the interior cell competence will facilitate better understanding of the mechanism of nervous system development.

Within four FRET pairs of fusion proteins, two of them, Mash1/E47 and Ngn2/E47, showed much higher FRET efficiencies in different regions of chick neural tube than in HEK293 cells, while NeuroD1/E47 and Ngn1/E47 pairs showed no significant differences between these conditions (Figure 5F), implying much more intimate interactions between E47 protein and Mash1 in the medial half or E47 protein and Ngn2 in the lateral half of developing neural tube than that in HEK293 cells. We speculate that conditions for bHLH protein-E box complex formation in HEK293 cells differ from those in chick embryo neural tubes because HEK293 cell is a kidney epithelial cell line with no potential to differentiate into neural cells, and the E-box containing regulatory regions of proneural gene targets might locate in regions of compact chromatin and might be inaccessible by the neural bHLH proteins. Overexpressed bHLH-GFP fusion proteins in HEK293 cells might result in loose and non-functional protein complexes in the absence of binding to cognate cis-elements [51]. In developing neural tube, however, neural progenitors can potentially differentiate into neurons and glia, and they normally express neural bHLH factors $[12,52-55]$. It is therefore reasonable to assume that in this context, the Eboxes of proneural gene targets are more easily accessible 
for binding by the bHLH neural regulators. Upon binding to E-boxes, bHLH protein dimmers may undergo conformational changes and form more compact complexes. As a result, DNA and protein complexes produce higher FRET efficiencies than the protein dimers alone [56]. Thereby, FRET efficiencies can be used to effectively describe the binding status of bHLH factors with their specific target sequences $[57,58]$.

During chick neural tube development, Mash1 and Ngn2 have complementary expression patterns in chick motor neuron specification. Ngn2 is mainly expressed in the lateral half, where motor neuron progenitors begin to acquire general neuronal properties and become post-mitotic, whereas Mash1 is excluded from this area of neural tube and mainly expressed in the medial half of the neural tube [59]. Consistent with these expression patterns, the Mash1/E47 and Ngn2/E47 pair showed higher FRET efficiencies in their expression regions of neural tube, suggesting that they might form the functional protein-DNA complexes with their target genes in the medial and lateral part, respectively. The complementary expression pattern for Mash1 and Ngn2 has been found in many locations of mouse developing nervous system and proved to be functionally relevant in these regions, as the ventral telencephalon progenitor and autonomic neurons for Mash1, and the dorsal telencephalon progenitor and sensory neurons for Ngn2 [40, 42, 45, 46]. Based on these observations, we propose that the complementary activities of Mash1 and Ngn2 during nervous system development might be conserved in vertebrates. Our work may help understand the cellular differences between the Mash1-expressing medial half cells and the Ngn2-expressing lateral half cells in chick motor neuronal differentiation.

In summary, we have established a GFP-based FRET method to detect bHLH protein-protein interactions in living mammalian cells, and also in developing neural tissues. With this method, our results show that different neural bHLH proteins might participate in protein complexes with different configurations during neurogenesis. This method could be used to further study the dynamics of protein-protein interactions in various stages of neural determination and differentiation both in vitro and in vivo.

\section{Acknowledgements}

We thank J Zhao for excellent technical support. This work was supported in part by National Natural Science Foundation of China (\#90208011,\#30300174,\#30470856 and \#30421005), National Key Basic Research and Development Program of China (\#2002CB713802 and \#2005CB522704), and Shanghai Key Project of Basic Science Research (\#04DZ14005 and \#04DZ05608).

\section{References}

1 Lillien L. Neural progenitors and stem cells: mechanisms of progenitor heterogeneity. Curr Opin Neurobiol 1998; 8:37-44.

2 Morrison SJ. Neuronal potential and lineage determination by neural stem cells. Curr Opin Cell Biol 2001; 13:666-667.

3 Bertrand N, Castro DS, Guillemot F. Proneural genes and the specification of neural cell types. Nat Rev Neurosci 2002; 3:517530.

4 Lee JE. Basic helix-loop-helix genes in neural development. Curr Opin Neurobiol 1997; 7:13-20.

5 Lee JE. NeuroD and neurogenesis. Dev Neurosci 1997; 19:2732.

6 Markus M, Du Z, Benezra R. Enhancer-specific modulation of E protein activity. J Biol Chem 2002; 277:6469-6477.

7 Ma Q, Sommer L, Cserjesi P, Anderson DJ. Mash1 and neurogenin1 expression patterns define complementary domains of neuroepithelium in the developing CNS and are correlated with regions expressing notch ligands. J Neurosic 1997; 17:36443652.

8 Sun Y, Nadal-Vicens M, Misono S, et al. Neurogenin promotes neurogenesis and inhibits glial differentiation by independent mechanisms. Cell 2001; 104:365-376.

9 Nakamura Y, Sakakibara S, Miyata T, et al. The bHLH gene hes1 as a repressor of the neuronal commitment of CNS stem cells. J Neurosci 2000; 20:283-293.

10 Wang S, Sdrulla A, Johnson JE, Yokota Y, Barres BA. A role for the helix-loop-helix protein Id2 in the control of oligodendrocyte development. Neuron 2001; 29:603-614.

11 Jessen U, Novitskaya V, Walmod PS, Berezin V, Bock E. Neural cell adhesion molecule-mediated neurite outgrowth is repressed by overexpression of HES-1. J Neurosci Res 2003; 71:1-6.

12 Lee JK, Cho JH, Hwang WS, et al. Expression of neuroD/BETA2 in mitotic and post-mitotic neuronal cells during the development of nervous system. Dev Dyn 2000; 217:361-367.

13 Murre C, McCaw PS, Baltimore D. A new DNA binding and dimerization motif in immunoglobulin enhancer binding, daughterless, MyoD, and myc proteins. Cell 1989; 56:777-783.

14 Murre C, McCaw PS, Vaessin H, et al. Interactions between heterologous helix-loop-helix proteins generate complexes that bind specifically to a common DNA sequence. Cell 1989; 58:537544.

15 Ellenberger T, Fass D, Arnaud M, Harrison SC. Crystal structure of transcription factor E47: E-box recognition by a basic region helix-loop-helix dimer. Genes Dev 1994; 8:970-980.

16 Ghosh I, Chmielewski J. A beta-sheet peptide inhibitor of E47 dimerization and DNA binding. Chem Biol 1998; 5:439-445.

17 Kenworthy AK. Imaging protein-protein interactions using fluorescence resonance energy transfer microscopy. Methods 2001; 24:289-296.

18 Xia Z, Liu Y. Reliable and global measurement of fluorescence resonance energy transfer using fluorescence microscopes. Biophysical J 2001; 81:2395-2402.

19 Clegg RM. Fluorescence resonance energy transfer. Curr Opin Biotechnol 1995; 6:103-110.

20 Sekar RB, Periasamy A. Fluorescence resonance energy transfer (FRET) microscopy imaging of live cell protein localizations. J Cell Biol 2003; 160:629-633.

21 Pollok BA, Heim R. Using GFP in FRET based applications. 
Trends Cell Biol 1999; 9:57-60.

22 Tang K, Wang C, Shen C, et al. Identification of a novel alternative splicing isoform of human amyloid precursor protein gene, APP639. Eur J Neurosci 2003; 18:102-108.

23 Sambrook J, Russell DW. Molecular cloning: a laboratory manual (third edition), New York: Cold Spring Harbor Laboratory Press, 2001.

24 Gao X, Bian W, Yang J, et al. A role of N-cadherin in neuronal differentiation of embryonic carcinoma P19 cells. Biochem Biophys Res Commun 2001; 284:1098-1103.

25 Witherow DS, Tovey SC, Wang Q, Willars GB, Slepak VZ. G beta 5.RGS7 inhibits G alpha q-mediated signaling via a direct protein-protein interaction. J Biol Chem 2003; 278:2130721313.

26 Birbach A, Bailey ST, Ghosh S, Schmid JA. Cytosolic, nuclear and nucleolar localization signals determine subcellular distribution and activity of the NF-kappaB inducing kinase NIK. J Cell Sci 2004; 117:3615-3624.

27 Niedick I, Froese N, Oumard A, et al. Nucleolar localization and mobility analysis of the NF-kappaB repressing factor NRF. J Cell Sci 2004; 117:3447-3458.

28 Kenworthy AK, Petranova N, Edidin M. High-resolution FRET microscopy of cholera toxin B-subunit and GPI-anchored proteins in cell plasma membranes. Mol Biol Cell 2000; 11:16451655.

29 Llopis J, Westin S, Ricote M, et al. Ligand-dependent interactions of coactivators steroid receptor coactivator-1 and peroxisome proliferator-activated receptor binding protein with nuclear hormone receptors can be imaged in live cells and are required for transcription. Proc Natl Acad Sci USA 2000; 97:4363-4368.

30 Chin JY, Knowles RB, Schneider A, et al. Microtubule-affinity regulating kinase (MARK) is tightly associated with neurofibrillary tangles in Alzheimer brain: a fluorescence resonance energy transfer study. J Neuropath Exp Neuro 2000; 59:966-971.

31 Centonze VE, Firulli BA, Firulli AB. Fluorescence resonance energy transfer (FRET) as a method to calculate the dimerization strength of basic helix-loop-helix (bHLH) protein. Biol Proced Online 2004; 6:78-82.

32 Yan Y, Bian W, Xie Z, et al. Stat3 signaling is present and active during development of the central nervous system and eye of vertebrates. Dev Dyn 2004; 231:248-257.

33 Hamburger V, Hamilton HL. A series of normal stages in the development of the chick embryo. J Morphol 1951; 88:49-92.

34 Mancini MG, Liu B, Sharp ZD, Mancini MA. Subnuclear partitioning and functional regulation of the Pit-1 transcription factor. J Cell Biochem 1999; 72:322-338.

35 Spector DL, Goldman RD, Leinwand LA. Cells: A laboratory manual, New York: Gold Spring Habor Laboratory Press, 1998.

36 Day RN, Periasamy A, Schaufele F. Fluorescence resonance energy transfer microscopy of localized protein interactions in the living cell nucleus. Methods 2001; 25:4-18.

37 Vermeer JE, Van Munster EB, Vischer NO, Gadella TW Jr. Probing plasma membrane microdomains in cowpea protoplasts using lapidated GFP-fusion proteins and multimode FRET microscopy. J Microsc 2004; 214:190-200.

38 Guillemot F. Vertebrate bHLH genes and the determination of neuronal fates. Exp Cell Res 1999; 253:357-364.

39 Lee JE, Hollenberg SM, Snider L, et al. Conversion of Xenopus ectoderm into neurons by NeuroD, a basic helix-loop-helix protein. Science $1995 ; \mathbf{2 6 8 : 8 3 6 - 8 4 4 . ~}$

40 Fode C, Gradwohl G, Morin X, et al. The bHLH protein Neurogenin 2 is a determination factor for epibranchial placode-derived sensory neurons. Neuron 1998; 20:483-494.

41 Farah MH, Olson JM, Sucic HB, et al. Generation of neurons by transient expression of neural bHLH proteins in mammalian cells. Development 2000; 127:693-702.

42 Guillemot F, Lo LC, Johnson JE, et al. Mammalian achaete-scute homolog 1 is required for the early development of olfactory and autonomic neurons. Cell 1993; 75:463-476.

43 Casarosa S, Fode C, Guillemot F. Mash1 regulates neurogenesis in the ventral telencephalon. Development 1999; 126:525-534.

44 Cau E, Casarosa S, Guillemot F. Mash1 and Ngn1 control distinct steps of determination and differentiation in the olfactory sensory neuron lineage. Development 2002; 129:1871-1880.

$45 \mathrm{Ma}$ Q, Chen Z, del Barco Barrantes I, de la Pompa JL, Anderson DJ. Neurogenin 1 is essential for the determination of neuronal precursors for proximal cranial sensory ganglia. Neuron 1998; 20:469-482.

46 Ma Q, Fode C, Guillemot F, Anderson DJ. Neurogenin1 and neurogenin2 control two distinct waves of neurogenesis in developing dorsal root ganglia. Genes Dev 1999; 13:1717-1728.

47 Miyata T, Maeda T, Lee JE. NeuroD is required for differentiation of the granule cells in the cerebellum and hippocampus. Genes Dev 1999; 13:1647-1652.

48 Kim WY, Fritzsch B, Serls A, et al. NeuroD1-null mice are deaf due to a severe loss of the inner ear sensory neurons during development. Development 2001; 128:417-426.

49 Poh A, Karunaratne A, Kolle G, et al. Patterning of the vertebrate ventral spinal cord. Int J Dev Biol 2002; 46:597-608.

50 Mizuguchi R, Sugimori M, Takebayashi H, et al. Combinatorial roles of olig2 and neurogenin2 in the coordinated induction of pan-neuronal and subtype-specific properties of motoneurons. Neuron 2001; 31:757-771.

51 Zheng L, Hoeflich KP, Elsby LM, et al. FRET evidence for a conformational change in TFIIB upon TBP-DNA binding. Eur J Biochem 2004; 271:792-800.

52 Gowan K, Helms AW, Hunsaker TL, et al. Crossinhibitory activities of Ngn 1 and Math1 allow specification of distinct dorsal interneurons. Neuron 2001; 31:219-232.

53 Simmons AD, Horton S, Abney AL, Johnson JE. Neurogenin2 expression in ventral and dorsal spinal neural tube progenitor cells is regulated by distinct enhancers. Dev Biol 2001; 229:327339.

54 Nakada Y, Parab P, Simmons A, Omer-Abdalla A, Johnson JE. Separable enhancer sequences regulate the expression of the neural bHLH transcription factor neurogenin 1. Dev Biol 2004; 271:479-487.

55 Parras CM, Schuurmans C, Scardigli R, et al. Divergent functions of the proneural genes Mash1 and Ngn2 in the specification of neuronal subtype identity. Genes Dev 2002; 16:324-338.

56 Hillisch A, Lorenz M, Diekmann S. Recent advances in FRET: distance determination in protein-DNA complexes. Curr Opin Struct Biol 2001; 11:201-207.

57 Powell LM, Zur Lage PI, Prentice DR, Senthinathan B, Jarman AP. The proneural proteins Atonal and Scute regulate neural target genes through different E-box binding sites. Mol Cell Biol 2004; 24:9517-9526. 
58 Turner EC, Cureton CH, Weston CJ, Smart OS, Allemann RK. Controlling the DNA binding specificity of bHLH proteins through intramolecular interactions. Chem Biol 2004; 11:69-77.

59 Lee SK, Pfaff SL. Synchronization of neurogenesis and motor neuron specification by direct coupling of bHLH and homeodomain transcription factors. Neuron 2003; 38:731-745.

Edited by Anning Lin 